\title{
Mind the Gap: Fostering Scholarship-into-Practice for Advanced Practice Nursing Students through Embedded Librarianship
}

\author{
Brenda Helen Sheingold ${ }^{1, *} \&$ Thomas Harrod ${ }^{2}$ \\ ${ }^{1}$ The George Washington University, School of Nursing, 2030 M Street, NW, Suite 3000, \\ Washington, D.C. 20036, USA \\ ${ }^{2}$ The George Washington University, Himmelfarb Health Sciences Library, 2300 Eye Street, \\ NW, Washington, DC, 20037, USA \\ *Corresponding author: The George Washington University, School of Nursing, $2030 \mathrm{M}$ \\ Street, NW, Suite 3000, Washington, D.C. 20036, USA. Tel: 202-994-4832. E-mail: \\ bsheingo@email.gwu.edu
}

Received: October 15, 2013 Accepted: November 22, 2013 Published: December 10, 2013

doi:10.5296/ije.v5i4.4421ＵRL: http://dx.doi.org/10.5296/ije.v5i4.4421

\begin{abstract}
In recent years, librarianship has been increasingly recognized as a critical component of inter-professional healthcare education. This manuscript describes how innovative coordination between libraries and university healthcare programs can remove the barriers to scholarship for graduate students who enroll in distance education (DE) programs. The authors examined the perceived impact of librarian embedment for DE nursing students graduating with master's degrees from George Washington University in 2013. Librarians were embedded in the first course in which they were enrolled in 2010 to support the mastery of scientific research skills. Analysis indicated that students strongly agreed that contact with embedded librarians in DE courses at the onset of a graduate school, improved their ability to engage in scholarly activities throughout their program of study. It also facilitated the integration of scholarship into practice (required for school accreditation) by allowing them to expeditiously retrieve research from databases and generate evidence for patient care delivery.
\end{abstract}

Keywords: distance education; librarians; nursing; accreditation 


\section{Background}

The embedding of librarians in DE courses represents one of the most significant shifts in the practice of Library Science in the 21st Century (Shumaker, 2009). The inclusion of health sciences librarianship, as one of many inter-professional components, has changed healthcare education delivery which, concurrent to the evolution of technology, has led to a host of new navigation practices and techniques to communicate and deliver knowledge (Juliani, Corrente, \& Dell'Acqua, 2011). A coordinated multidisciplinary approach is becoming the norm, requiring University level professionals to leverage their expertise differently and create innovative opportunities to interface with students (Juliani et al. 2011).

Several best practices have been identified when health sciences librarians are embedded into distance education for beginning master's level nursing students, such as: focused on-line tutorials, the acquisition of literature synthesis skills, and technological proficiency (Sullo, Harrod, Butera \& Gomes, 2012). Additionally, embedded health sciences librarians are an advantage to time-challenged faculty by preparing students to utilize the library in a more independent manner (Guillot, Stahr, \& Meeker, 2012).

The American Association of Colleges of Nursing (AACN) has developed the Essentials of Master's Education in Nursing, a framework which closely aligns with the desired outcomes achievable by an embedded health sciences librarian. There are nine essential elements that graduate level nursing programs are expected to address at a high level - they are as follows:

I. Background for Practice from Sciences and Humanities

II. Organizational and Systems Leadership

III. Quality Improvement and Safety

IV. Translating and Integrating Scholarship into Practice

V. Informatics and Healthcare Technologies

VI. Health Policy and Advocacy

VII. Interprofessional Collaboration for Improving Patient and Population Health Outcomes

VIII. Clinical Prevention and Population Health for Improving Health

IX. Master's Level Nursing Practice

(Source: American Association of Colleges of Nursing Essentials, 2011)

These nine Essentials form the foundation for curriculum content in graduate level nursing courses. To achieve accreditation by the Commission on Collegiate Nursing Education (CCNE) or by the National League for Nursing Accrediting Commission (NLNAC), a nursing program is required to demonstrate how they meet the nine Essentials, making the ease of student access to embedded health sciences librarians in courses a critical component in the sustainability of a program (Dracup, 2012).(Note 1) 
In addition to providing key support to the achievement of accreditation standards, innovative access to health sciences librarians supports the Affordable Care Act (ACA) provisions for educating the APRN workforce to increase access to primary care in the U.S. (American Nurses Association, 2012).

The main focus of this study was to explore the perceived effect embedded health sciences librarians have had on the ability of APRN students to meet AACN Essential IV. Translating and Integrating Scholarship into Practice at the conclusion of their program of study (POS). Embedded health sciences librarians were assigned to the first courses in which these students enrolled in 2010, and they graduated during the academic year 2012-2013.

Additionally, we sought to highlight some of the key lessons learned by health sciences librarians who were embedded in these distance education classes. More and more students are choosing online post-secondary education options and these distance education students interact with their institution's library systems differently than on-campus students (McDonald, 2010). In this article, we offer recommendations to health sciences librarians as they adapt to this growing population.

\section{Purpose}

1. To determine the congruence of the embedded health sciences librarian experience for graduating MSN nurses with their ability to meet the AACN Essential of Translating and Integrating Scholarship into Practice.

2. To identify how embedded health sciences librarians can support the preparation of APRNs to meet the national demand for better healthcare services as defined by ACA.

\section{Aim}

To examine the perceived effect of having an embedded health sciences librarian in their first course on two outcomes, (1) enhanced ability to function as scholars during graduate school, and (2) support of the AACN Essential of translating scholarship into practice.

\section{Significance}

In recent years, health sciences librarianship has been increasingly recognized as a critical component of inter-professional healthcare education. Furthermore, the presence of library skill components in nursing education courses aligns closely with the AACN Essentials of Master's Education framework. As a result, innovative coordination between libraries and university healthcare programs is evolving and promises to yield further substantive benefits for students in the future. 


\section{Methods}

\subsection{Design}

An online survey instrument was developed and administered to a convenience sample of School of Nursing (SON) DE students graduating during the summer of 2012 - summer of 2013 academic year from masters level programs at The George Washington University. The survey was sent to a total of 102 MSN graduates, of whom 40 replied. Potential questions were drafted based upon the variety of health sciences librarian services and communication options that participants were offered in their first semester of graduate school as well as items from The Essentials of Master's Education in Nursing manual published by AACN (2011). The manual identifies six specific elements or skills that are required to translate and integrate scholarship into practice. These served as the foundation for survey questions that aligned AACN accreditation elements with the concept of embedding health sciences librarians in distance education courses.

Content validity of the instrument was established based upon researcher review of the current literature and review and edit of the survey questions independently by a group comprised of health sciences librarians, nursing faculty members, and graduating MSNs. The final survey consisted of 10 questions related to student perception of the embedded health sciences librarian experience and 6 questions related to alignment with translating scholarship into practice. These two sets of questions employed a five-point Likert scale with 1 indicating Strongly Agree and 5 indicating Strongly Disagree. In addition, participants were asked to respond to 6 demographic questions.

\subsection{Human Subjects Consideration}

The study was approved by The George Washington University Internal Review Board (IRB) and all participants provided informed consent.

\subsection{Statistical Analysis}

Data collected from the survey was analyzed using the Statistical Product and Service Solutions (SPSS) version 20.

\section{Results}

Demographic data from the study are displayed in Table 1 . The gender of the subjects was $90 \%$ female and $10 \%$ male, with $62.5 \%$ working full-time while completing APRN programs. The majority of participants were graduating as Family Nurse Practitioners (47.5\%), followed by Adult Nurse Practitioners and Healthcare Quality majors (17.5\% each), Leadership majors (12.5\%) and Clinical Research Management (5\%). Most of the participants were employed by hospitals (53\%), with smaller percentages practicing in ambulatory care centers, home health, hospice, school health or correctional services. 
Table 1: Demographics 2013, Vol. 5, No. 4

\begin{tabular}{lcc}
\hline $\begin{array}{l}\text { Demographic } \\
\text { variable }\end{array}$ & N & \% \\
\hline Gender & & \\
Male & & 10 \\
Female & 4 & 90 \\
TOTAL & 36 & 100.0 \\
\hline Tenure (years in nursing) & \\
1-5 & 9 & 22.5 \\
6-11 & 15 & 37.5 \\
12-15 & 6 & 15 \\
16-20 & 4 & 10 \\
21-25 & 2 & 5.0 \\
More than 25 & 4 & 10.0 \\
TOTAL & 40 & 100.0 \\
& & \\
Education & & \\
Bachelor's & 27 & 67.5 \\
Degree & & \\
Master's & 13 & 32.5 \\
Degree \\
TOTAL
\end{tabular}




\section{Macrothink}

\subsection{Embedded Health Sciences Librarian Experience}

The Likert scale questions were reverse coded during analysis so that a higher score meant a higher degree of agreement with the variable. An examination of frequencies indicated that student contact with embedded health sciences librarians generally occurred through the Blackboard discussion boards (60\%); direct email (55\%) and during synchronous, live, Collaborate sessions in Blackboard (40\%). A few chose direct telephone contact (10\%). These percentages add up to more than $100 \%$ because students utilized more than one mode of contact. Overall almost $3 / 4$ of the respondents chose to directly communicate with the embedded health sciences librarian as demonstrated in Figure 1. The primary reasons for the contact are displayed in Figure 2.

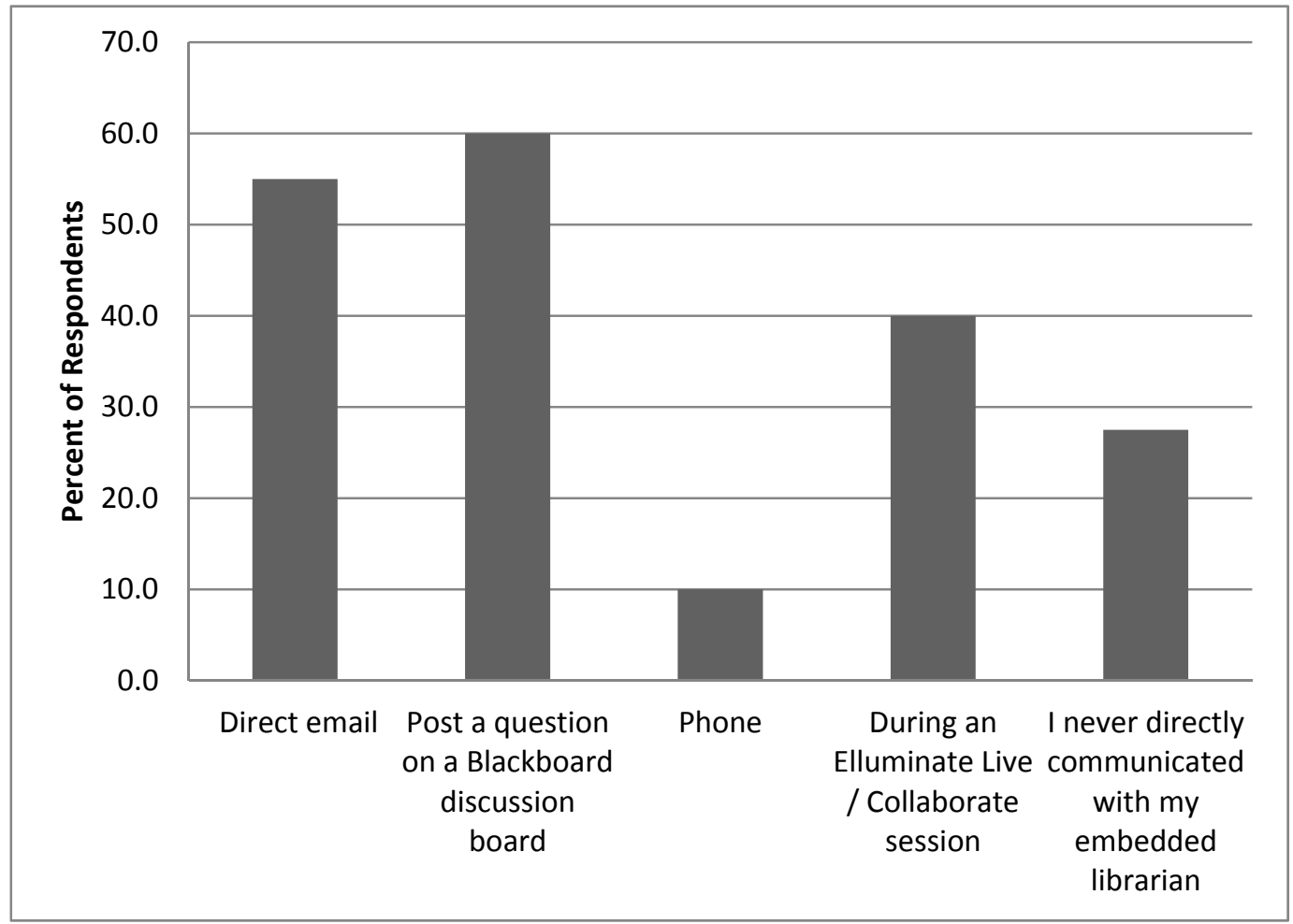

Figure 1: By which of the following methods did you communicate with the embedded librarian in your class or classes? (CHOOSE ALL THAT APPLY) 


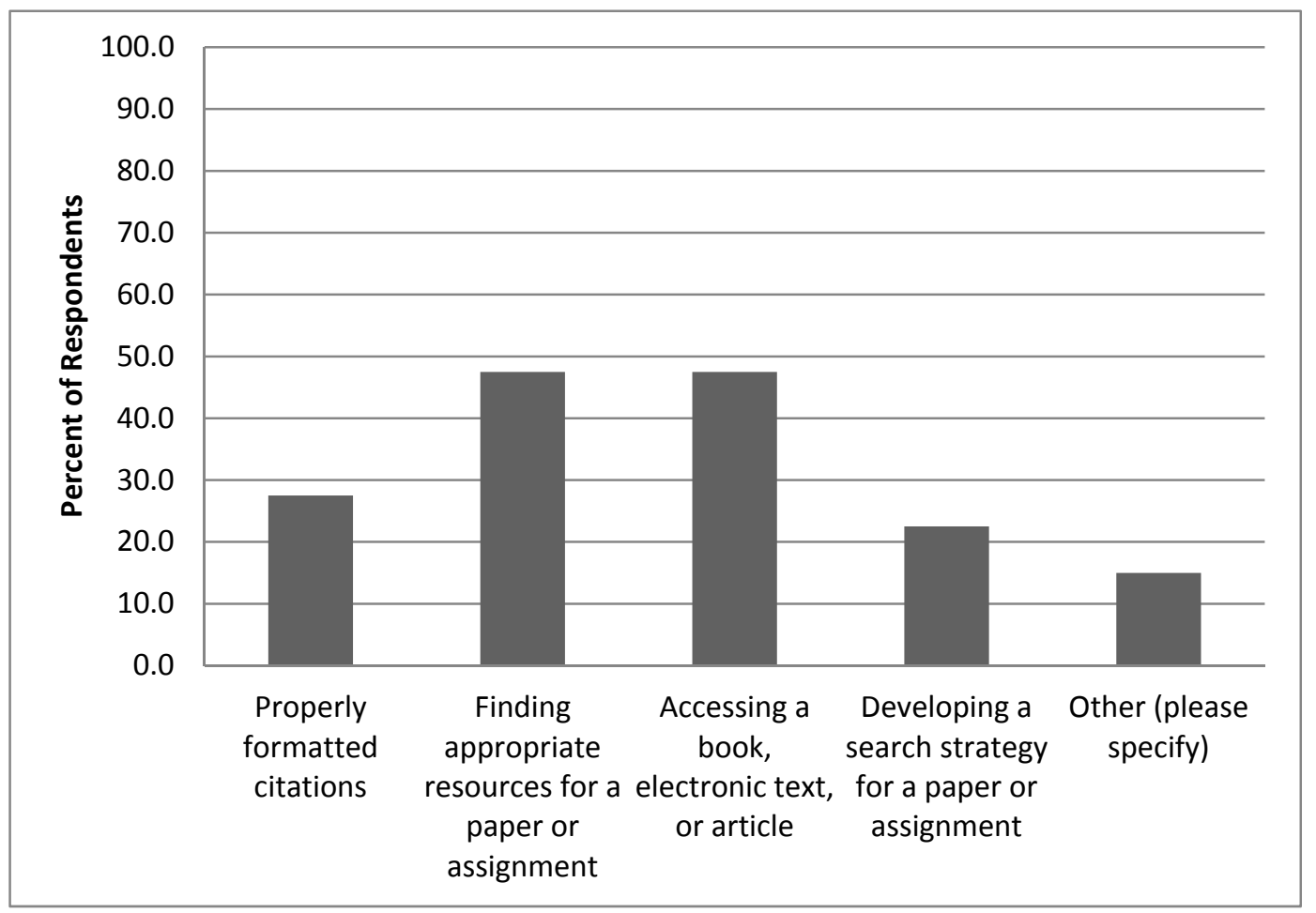

Figure 2: If you contacted the embedded librarian in one or more of your classes - please describe the topic of your inquiry

\subsection{Alignment with AACN Essential IV. Translating and Integrating Scholarship into Practice}

The Cronbach's Alpha coefficient of .914 indicated a relatively high level of reliability, (internal consistency) for this sub-set of questions (SPSS, 2010). Reverse coding was also employed for this set of questions, and participant perception of alignment with AACN Essential IV had an overall mean score 3.46, indicating agreement that the embedded health sciences librarian experience facilitated the achievement of translating and integrating scholarship into practice. Table 2. displays these questions and the related mean, median and mode. 


\section{Macrothink}

International Journal of Education

ISSN 1948-5476

2013, Vol. 5, No. 4

Table 2: AACN Essential IV. Questions and Corresponding Mean, Median, Mode

\section{Survey Questions Related to Translating and \\ Integrating Scholarship Into Practice}

Mean Median Mode

The embedded librarian experience helped me integrate

theory, evidence, clinical judgment, research, and

4.00

3

inter-professional perspectives.

The embedded librarian experience helped me become an

3.00

advocate for the ethical conduct of research and

translational scholarship.

The embedded librarian experience helped me articulate

to a variety of audiences the evidence base for practical decisions, including the credibility of sources of information and the relevance to the practice problem confronted.

The embedded librarian experience helped me participate

in, leading when appropriate, collaborative teams to improve care outcomes.

The embedded librarian experience helped me apply

practice guidelines to improve practice and care

environment.

The embedded librarian experience helped me to perform rigorous critique of evidence derived from databases to

generate meaningful evidence for nursing practice.

Participants were given the opportunity to write-in examples of how they apply the skills taught to them by embedded health sciences librarians in their daily clinical practice. A cross-walk of quotes aligned with the six AACN elements of translating and integrating scholarship into practice is displayed in Table 3. 
Table 3: AACN Essential IV. Elements and Corresponding Student Quotes

\begin{tabular}{cc}
\hline $\begin{array}{c}\text { Six Elements of AACN Essential IV. } \\
\text { Translating and Integrating Scholarship } \\
\text { Into Practice }\end{array}$ & $\begin{array}{c}\text { Corresponding Verbatim Student Quotes } \\
\text { Regarding the Application of Skills } \\
\text { Taught by Health sciences librarians }\end{array}$ \\
\hline
\end{tabular}

Integrate theory, evidence, clinical judgment, research, and interprofessional perspectives using translational processes to improve practice and associated health outcomes for patient aggregates.

Advocate for the ethical conduct of research and translational scholarship (with particular attention to the protection of the patient as a research participant).

"In my clinical practice, I look up information about disease processes.”

Articulate to a variety of audiences the evidence base for practice decisions, including the credibility of sources of information and the relevance to the practice problem confronted.

Participate, leading when appropriate, in collaborative teams to improve care outcomes and support policy changes through knowledge generation, knowledge dissemination, and planning and evaluating knowledge implementation.

Apply practice guidelines to improve practice and the care environment.

Perform rigorous critique of evidence derived from databases to generate meaningful evidence for nursing practice.

"I use the library heavily. I use it every day for papers, discussion research, and for protocols of patient care."

"I’m actually researching some information to present at a local school.”

"Use the library all of the time - this is wonderful!

I use it for our nursing team on a regular basis."

"I did some research on appropriate bowel hygiene protocols for the elderly."

"I was able to access multiple articles that supported work at my organization.”

"I use VPN, Pubmed, Medline, Bates videos and tons of others.”

“Journals, search engines, books, everything."

\section{Discussion}

As healthcare reform expands, and APRNs are charged with adapting their practice to better reflect the ideals of evidenced-based practice, the roles of nursing faculty and health sciences librarians will increasingly overlap with regard to innovative education. The evidence from this study suggests that APRN students are supported in the achievement of AACN-MSN Essential IV when health sciences librarians are embedded in core courses at the onset of 
graduate school. Additionally, 62.5\% of study participants 'Strongly Agreed' or 'Agreed' that embedded health sciences librarians were helpful and provided a valuable addition to the learning environment. We have presented data that supports the perception that our librarians can help address the AACN-MSN Essential of Translating and Integrating Scholarship into Practice through value-added collaboration that can potentially cultivate a successful accreditation review.

Furthermore, these results provide an example of how health sciences librarians can identify opportunities to serve new or previously under-served constituencies or serve old constituencies in a new way. Students contacted their embedded librarians to get help with 'typical' academic library patron issues such as identifying and locating resources and, to a lesser extent, formatting citations and developing overall research strategies.

To offer support to these students, we embraced new modes of communication - the creation of an 'Ask the Librarian' discussion board on the course Blackboard page as well as the use of real-time, online instructional programs in order to connect with remote students.

\section{Limitations}

The study does have some limitations that could be addressed in future research. First, there is insufficient literature that has been published on the practice of embedding librarians in distance education courses. Additionally, there is no baseline with which to compare the calculated levels of the AACN Essentials and the embedded librarian experience. The timing of the survey may also have been a limitation, since our focus was on new graduates two to three years after their first encounter with embedded librarians in initial courses.

\section{Conclusions and Implications for Policy, Delivery or Practice}

These results support the concept of embedding health sciences librarians in online classes. Embedded librarians can provide an important link to understand and develop the scholarship necessary for evidence-based practice, a mandate of healthcare reform. Additionally, the establishment of a strong librarian partnership supports the national accreditation requirements for any school within a university that focuses on clinical practice, be it pharmacy, physical therapy, medicine, dentistry or nursing.

From the perspective of the health sciences librarian there are numerous implications from this work. First of all, as familiar existing paradigms shift and evolve, librarians must seek new ways to prove their value and show that health sciences librarians can adapt to new circumstances. Second, health sciences librarians should feel empowered to approach instructional faculty and develop unique means to integrate librarian assistance into their programs. As seen in the results discussed above, this assistance is greatly appreciated by students and its implementation requires very little investment of time or effort from the teaching faculty. Third, health sciences librarians should make an effort to explore new technologies - even when there is not an imminent or obvious use for them - adding new 
technologies to their 'tool kit' can pay off in unexpected, yet fruitful ways. These technologies can allow health sciences librarians to offer creative solutions to previously insoluble problems. Fourth, the use of pertinent standards (such as the AACN Essentials of Master's Education) to guide and evaluate librarian efforts will help them connect with potential partners.

Embedded librarians promote inter-professional healthcare education, and establish librarian skills as a critical component to close the scholarship-into-practice gap.

\section{Acknowledgements}

The authors gratefully acknowledge Anne Linton MS, AHIP Director Himmelfarb Health Sciences Library George Washington University and Alex Gomes MSLS, MT, AHIP Associate Director Himmelfarb Health Sciences Library, George Washington University for their assistance in reviewing the manuscript prior to submission.

\section{References}

American Association of Colleges of Nursing. (2011). The essentials of master's education in nursing [Internet]. Washington, DC: American Association of Colleges of Nursing; $\begin{array}{lllll}\text { Retrieved } & 21 & \text { March } & 2011 & \text { from }\end{array}$ http://www.aacn.nche.edu/educationresources/MastersEssentials11.pdf

American Nurses Association. (2012). Healthcare transformation: the Affordable Care Act and more [Internet]. Silver Spring, MD: American Nurses Association; Retrieved 26 June 2013] from nursingworld.org/MainMenuCategories/Policy-Advocacy/HealthSystemReform/Afforda bleCareAct.pdf $>$.

Dracup, K. (2012). Master's nursing programs [Internet]. Washington, DC: American Association of Colleges of Nursing; Retrieved from http://www.aacn.nche.edu/education-resources/msn-article

Guillot L., Stahr B., \& Meeker B. (2010). Nursing faculty collaborate with embedded librarians to serve online graduate students in a consortium setting. J Lib Inf Serv Distance Learn, 4(1/2), 53-62. http://dx.doi.org/10.1080/15332901003666951

Juliani CM, Corrente JE, \& Dell'Acqua MC. (2011). Comparing the teaching-learning process with and without the use of computerized technological resources. Comput Nurs Inform, 29(4), 212-20. http://dx.doi.org/10.1097/NCN.0b013e3182285c2e

McDonald BS. (2004). Blended learning and sense of community: A comparative analysis with traditional and fully online graduate courses. Int Rev Res Open Distance Learn, 5(2), 1-13.

Shumaker D. (2009). Who let the librarians out? Embedded librarianship and the library 
manager. Reference and User Serv Q, 48(3), 239-257. http://dx.doi.org/10.1097/10.5860/rusq.48n3

SPSS Inc. (2010). IBM SPSS Statistics Gradpack 20 for Windows. Upper Saddle River, NJ: Prentice-Hall, Inc.

Sullo E., Harrod T., Butera G., \& Gomes A. (2012). Rethinking library service to distance-education students: analyzing the embedded librarian model. Med Reference Serv Q, 31(1), 25-33. http://dx.doi.org/10.1080/02763869.2012.641822

Note

Note 1. The American Association for Colleges of Nursing report that currently there are 330 accredited Masters of Science in Nursing programs in the United States.

\section{Copyright Disclaimer}

Copyright reserved by the author(s).

This article is an open-access article distributed under the terms and conditions of the Creative Commons Attribution license (http://creativecommons.org/licenses/by/3.0/). 